\title{
Foreword
}

Special Focus Issue - Pharmaceutical Patent Law: Expert

Perspectives From Around the Globe

\section{Pharmaceutical patent law: expert perspectives from around the globe}

First draft submitted: 2 June 2016; Accepted for publication: 6 June 2016; Published online: 12 July 2016

This special issue highlights pharmaceutical patent practice around the world. Generally speaking, patents in the pharmaceutical field are unique and many practitioners have encountered a number of problems in order to secure efficient and robust patent portfolios around the globe. Additionally, in order to enforce intellectual property (IP) rights in this field, it is imperative to adhere to regulations, such as obtaining market authorization, which makes life more difficult.

This special issue focuses on the unique patent practice in various countries around the world. Methods of treatment, surgery and diagnosis are some of major topics in pharmaceutical patent protection, and a number of the articles in this special issue discuss this [1-6]. Additionally, how to protect second medical use and other types of drug repositioning and novel dosage regimen are also touched upon in the issue [7-9]. As such, I strongly believe that this issue will assist readers in developing an effective patent portfolio that should allow them to enforce them in a sophisticated manner.

\section{Harmonization or local practice?}

IP harmonization around the world is difficult. As discussed by Hoa Binh and Minh Phuong in this special issue, each country has its own unique rules and practices governing the pharmaceutical patent system [10]. Although an Agreement on TradeRelated Aspects of Intellectual Property Rights (TRIPS) [11], which aims to harmonize IP systems around the world, has now come into effect, it allows the member states to create a novel convention or the like. The Trans-Pacific Partnership agreement (TPP), which is discussed by Hoa Binh and Minh Phuong in their article, is an example. The TPP was finally signed in early February this year after more than 19 rounds of tough negotiations spanning over 5 years. In the TPP agreement, pharmaceutical IP rights protection was one issue of much contention [12]. With respect to the patentable subject matter, the agreement generally allows patent protection for pharmaceutical subject matter in the form of a product, but allows certain exceptions, such as the member states can exclude methods of treatment, diagnosis and surgery from patentable subject matter.

Enablement and written description or utility requirements also vary among nations. Some jurisdictions strictly require pharmacological data in a patent application, some may not and supplemental, post-filing data are usually accepted. These differences in patent examination practice may also be considered when formulating a business decision.

Regarding patent term extension, Article 18.48.1 stipulates 'With respect to a pharmaceutical product that is subject to a patent, each Party shall provide to within one adjust patent to compensate the owner for unreasonable reductions to the effective patent term resulting from the marketing approval process...' However, a number of states do not have a patent term extension system, especially in countries in which no or very few innovator drug companies exist, which results in difficulty in implementing these rules, since it is anticipated that most sectors will be negatively impacted by introducing the system.

Data protection is also an issue that attracted much debate among the members

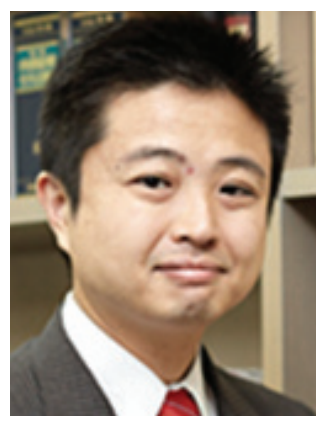

Takeshi S Komatani SHUSAKU.YAMAMOTO, 17th Floor, Grand Front Osaka Tower, C3-1 Ofuka-cho, Kita-ku, Osaka, 530-0011 Japan

tskomatani@shupat.gr.jp 
during negotiation of the TPP agreement. It is clear that the data protection system is not an extension of protection of the patent system, but is another form of protection for results from clinical trials and not to the invention as such, as is the case for patents. In the agreement, Article 18.50 stipulates 'Protection of Undisclosed Test or Other data' and states 'if a Party requires, as a condition for granting marketing approval for a new pharmaceutical product, the submission of undisclosed test or other data concerning the safety and efficacy of the product, that Party shall not permit third persons, without the consent of the person that previously submitted such information, to market the same or a similar product on the basis of: (i) that information; or (ii) the marketing approval granted to the person that submitted such information for at least five years from the date of marketing approval of the new pharmaceutical product in the territory of the Party...' As such, the TPP requires member states to introduce a data protection system. However, in Japan, for example, there is no affirmative protection system of clinical data, but rather passive system, which is called the re-examination system, where a third party cannot rely on innovator drug company's clinical trial data during this reexamination system. Members of the TPP have their own specific issues, especially within the pharmaceutical field relating not only to the patent system per se, but also regulatory science.

As such, it is expected that member states will face difficulties when they implement these rules in their national legislation. I believe that, in the next couple of decades, harmonizing IP systems (especially in the field of pharmaceutical industry), will continue to be a global problem.

\section{Collaboration with IP practitioners}

Those who read this special issue may be from the research and development $(\mathrm{R} \& D)$ field or regulatory affairs field, or may be IP practitioners. Regardless of your profession, I believe that the importance of collaboration between IP and R\&D practitioners will become an important factor in obtaining fruit-

\section{References}

1 Baklaci E, Altınay M. Second medical use in Turkey. Pharm. Pat. Anal. 5(4), 199-201 (2016).

2 Koshy N. Patenting strategies - perspective from the Cooperation Council for the Arab States of the Gulf. Pharm. Pat. Anal. 5(4), 217-226 (2016).

3 Komatani TS. Global future perspectives from Japan. Pharm. Pat. Anal. 5(4), 227-235 (2016). ful results in pharmaceutical research. A number of pharmaceutical companies have an IP department and regulatory affairs department that are independent from $R \& D$. As discussed in this issue [13,14], $\mathrm{R} \& \mathrm{D}$ and IP sectors should collaborate with each other in order to ensure efficient and effective patent filing. IP and regulatory affairs departments should improve communications with one another to achieve a more holistic view of IP.

This is a very exciting time for discussing patent and IP systems in the pharmaceutical industry and I am very thankful to the authors who have shared their expertise and insights in this special issue. I believe that this issue will provide a valuable platform for discussion and will appeal to those working in all areas of the patent and IP system.

\section{Disclaimer}

This commentary describes the opinions and observations of the author as a Japanese patent attorney and does not necessarily represent the viewpoints of the author's employers or author's firm. By its nature, the subject article provides the author's general opinion, and necessarily limited discussion of various topics; it does not purport to give specific legal advice or a substitute for legal counsel. As legal advice must be tailored to the specific circumstances of each case, nothing provided herein should be used as a substitute for advice of competent counsel. The author and the author's firm assume no liability for the use or interpretation of information contained herein. The author and the author's firm expressly disclaim all liability in respect of anything done or omitted to be done wholly or partly in reliance of this material.

\section{Financial \& competing interests disclosure}

The author has no relevant affiliations or financial involvement with any organization or entity with a financial interest in or financial conflict with the subject matter or materials discussed in the manuscript. This includes employment, consultancies, honoraria, stock ownership or options, expert testimony, grants or patents received or pending, or royalties.

No writing assistance was utilized in the production of this manuscript.

4 Shin YS. Past, present and future of pharmaceutical patents under Korea-US Trade Agreement. Pharm. Pat. Anal. 5(4), 237-248 (2016)

5 Han W, Luo J. Patenting pharmaceuticals in China. Pharm. Pat. Anal. 5(4), 249-259 (2016).

6 Aumand L, Norman J. Pharmaceutical patent law: the Canadian perspective. Pharm. Pat. Anal. 5(4), 271-279 (2016). 
7 Baklaci E. Ibid.

8 Komatani TS. Ibid.

9 Han W, Luo J. Ibid.

10 Binh NH, Dieu H. How might the TPP impact on pharmaceutical sector in Vietnam? Pharm. Pat. Anal. 5(4), 261-270 (2016).

11 Uruguay Round Agreement: TRIPS Trade-Related Aspects of Intellectual Property Rights.

www.wipo.int/treaties/en/text.jsp?file_id=305907
12 Trans-Pacific Strategic Economic Partnership agreement (TPP), Chapter 18 intellectual property, section A: general provisions.

https://ustr.gov

13 Komatani TS. Ibid.

14 Shin YS. Ibid. 